\title{
A comparative study on efficacy of various disinfectant systems on dental impression surfaces: In vivo study
}

\author{
Datla Durga Devi ${ }^{1, *}$, R. Himabindu ${ }^{2}$ \\ ${ }^{1}$ PG Student, ${ }^{2}$ Professor, Dept. of Prosthodontics, Gitam Dental College and Hospital, Visakhapatnam, Andhra Pradesh, India \\ *Corresponding Author: \\ Email: drdevidatla@gmail.com
}

\begin{abstract}
Purpose: To evaluate the microbial load on impressions and the efficacy of various disinfectants on reducing microorganisms from the impression surface after disinfection.

Materials and Methods: A total of 50 dentulous impressions were made for dentate patients each of age 20 to 50 years using Alginate and Polyvinyl siloxane. Impression compound and zinc oxide eugenol were used for edentulous patients each of age 50 to 70 years, total of 50 edentulous impressions were made. Samples were collected with the help of an 8 mm diameter sterile cork borer from each individual impression. Alginate, ZOE and impression compound had 100 samples each. Polyvinyl siloxane had 125 samples. Out of 100 samples the first group of the sample was assigned as control $(n=25)$, the second group of samples $(n=25)$ were immersed in $2 \%$ Glutaraldehyde, the third group of samples $(n=25)$ were sprayed with Dimenol, the fourth group of samples $(n=25)$ were placed in the ultraviolet light chamber. For polyvinyl siloxane, an additional fifth sample group ( $\mathrm{n}=25)$ was subjected to microwave radiation of $650 \mathrm{~W}$. The viability of microorganisms that can persist after rinsing and disinfecting the impression surface was tested by inoculating in nutrient media. The colony forming units were counted and compared with the control group. The data were documented and statistically analyzed.

Results: There was a significant difference in the count among the control group and the disinfectant groups. Microbial load found on control groups was taken as $100 \%$. Alginate samples which were disinfected with $2 \%$ Glutaraldehyde, Dimenol spray and UV light showed microbial load 31\%, 46\%, 44\% respectively, Polyvinylsiloxane samples showed microbial load 35\%, 53\%, $48 \%$ and $0 \%$ with microwave radiation respectively. Impression compound samples showed 32\%, 49\%, 49\% respectively \& Zinc oxide eugenol samples with $2 \%$ Gluteraldehyde, dimenol and UV showed a load of $39 \%, 51 \%, 51 \%$ respectively.

Conclusion: $2 \%$ Glutaraldehyde showed higher efficacy in reducing the microflora compared to Dimenol spray and UV radiation. There was complete removal of microorganisms with Microwave radiation.
\end{abstract}

Keywords: Impression materials, Disinfectants, Microbial load.

\section{Introduction}

Oral microflora is inhabited by numerous microorganisms. Dental impressions and casts made from contaminated saliva and blood pose serious risk to dental personnel. Sterilization is the process by which all forms of microorganisms such as viruses, bacteria, fungi, and spores are destroyed. ${ }^{1}$ Disinfection is generally a less lethal process when compared to sterilization. It virtually eliminates all recognized pathogenic microorganisms, but not necessarily all microbial forms (bacterial endospores), on inanimate objects. ${ }^{2}$ Disinfectants used in dental settings must be registered as a hospital disinfectant by Environmental Protection Agency. ${ }^{1}$ Surface disinfection will inactivate the infectious agents and reduce the spread of infection to dental personnel from contaminated impressions. The purpose of this article is to evaluate the microbial load on impression and the efficacy of various disinfectants on the reduction of microorganisms from the impression surface after disinfection.

\section{Materials and Methods}

Selection of patient: A total of 50 dentate patients of age group between 20 to $50 \mathrm{yrs}$ and 50 edentulous patients of age group between 50 to $70 \mathrm{yrs}$ were selected based on medical and dental histories. They had not received antibiotic, antifungal or any form of immunosuppressive or chemotherapy for the past 6 months. Selected patients had not received any oral hygiene measures or specific tooth brushing instructions and were not using any mouth rinse. The materials used in the study have been listed in Table 1 .

Table 1: Materials used in the study

\begin{tabular}{|l|l|}
\hline Alginate & Algitex, Mumbai \\
\hline $\begin{array}{l}\text { Polyvinyl Siloxane [putty } \\
\text { and light body] }\end{array}$ & Adsil, Mumbai \\
\hline Impression compound & Y-Dent, New Delhi \\
\hline Zinc oxide eugenol & DPI, Mumbai \\
\hline $2 \%$ glutaraldehyde & $\begin{array}{l}\text { Raman and Well Pvt. } \\
\text { Ltd, Mumbai }\end{array}$ \\
\hline Dimenol spray & SEPTODONT \\
\hline UV Chamber & $\begin{array}{l}\text { STERILIZE model no: } \\
4538\end{array}$ \\
\hline Microwave & Samsung \\
\hline
\end{tabular}

\section{Sample size}

For dentate patients impressions were made using alginate and polyvinyl siloxane and for edentulous patient's impression compound and zinc oxide eugenol paste were used. A total of 25 impressions were made 
with each impression material. Four samples were made from each impression of alginate, impression compound and zinc oxide eugenol paste impressions which make 100 samples for each. Five samples were made from each polyvinyl siloxane impressions which make 125 samples.

The study was conducted to compare the efficacy of three disinfectant systems on the surfaces of dental impression materials. Since polyvinyl siloxane could tolerate heat, the efficacy of microwave was also evaluated on polyvinyl siloxane impression.

\section{Impression Making}

Prior to impression making sterile protocol was established. Maxillary perforated stock trays were used in dentate patients to make maxillary arch impressions with alginate and polyvinyl siloxane. Non-perforated edentulous stock trays were used for making impressions with impression compound. For zinc oxide eugenol special tray was fabricated with autopolymerizing acrylic resins for making impressions. Special trays were disinfected by immersion method in $2 \%$ glutaraldehyde for $10 \mathrm{~min}$.

\section{Sample Collection and Disinfection}

Four samples for alginate and five samples for polyvinyl siloxane were punched with the help of an $8 \mathrm{~mm}$ diameter sterile cork borer from each impression. For alginate and polyvinyl siloxane impression the sites selected for removal of the samples are molar and premolar regions. The fifth site of polyvinyl siloxane was collected from central incisor region. This was done due to more bacterial colonization at the sites of tooth region. Palatal surfaces were selected for impression compound and zinc oxide eugenol impressions. For edentulous patients the bacteria are more confined to the mucosal surface, therefore, the palatal surface was selected. (Fig. 1,2)

Twenty five samples in each subgroups are named as a control group, $2 \%$ Glutaraldehyde group, dimenol group and UV group for alginate, impression compound and zinc oxide eugenol. The first sample was kept as control, second was immersed in $2 \%$ Glutaraldehyde for $10 \mathrm{~min}$, third was sprayed with dimenol and left for $15 \mathrm{~min}$, the fourth sample was placed in an ultraviolet light chamber at $254 \mathrm{~nm}$ wavelength for $3 \mathrm{~min}$. For polyvinyl siloxane, an additional fifth sample was subjected to a microwave of $650 \mathrm{~W}$ for $7 \mathrm{~min}$. For immersion according to manufacturer's instructions $100 \mathrm{ml}$ of $2 \%$ Glutaraldehyde was poured into sterilized kidney tray to which $11 \mathrm{ml}$ of activator was added. After addition of the activator, the solution turned into green color and was ready for disinfection. For dimenol spray single spray was done evenly onto the impression material. UV chamber used in this study had $254 \mathrm{~nm}$ wavelength with 2 bulbs of 8 watts each and was exposed for $3 \mathrm{~min}$.

Disinfection was performed at room temperature. In order to remove any traces of the disinfectant from the impression surface, the specimens were again rinsed with distilled water for $15 \mathrm{~s}$. The samples were collected in a sterile container and $5 \mathrm{ml}$ of sterile water was added. This sample was sent to the microbiological laboratory within $30 \mathrm{~min}$ of disinfection (Fig. 3-6)

\section{Microbiological procedure}

The sample containers were sent to the Department of Microbiology, GIMSR. The sample containers were agitated so that the microorganisms get separated from the sample forming the microbial suspension. The spread plate method was done which required a diluted mixture of microorganisms. During inoculation, the cells were spread over the surface of a solid agar medium with a sterile L shaped bent glass rod while the Petri dish was spun on a turntable. Blood agar plates were used for the isolation of Gram positive and Gram negative cocci whereas Mac Conkey agar plates were used for the isolation of Gram negative bacilli. All the plates were incubated aerobically at $37^{\circ} \mathrm{C}$ for 24 hours. The number of colonies that appeared after incubation were expressed as CFUs (colony-forming units), and then the CFUs were counted. The isolates were stained with Gram's stain and were identified using standard microbiological methods. Colony characteristics found in culture media and gram staining of the isolated organisms were identified and confirmed the microbial growth. Colony forming units (CFU) were counted and the results were documented. The documented results were sent for statistical analysis. (Fig. 7-13)

\section{Statistical Analysis}

Chi-square was calculated, which is the sum of the squared difference between observed (o) and the expected (e) data divided by the expected data in all possible categories.

\section{Results}

A significant reduction in the microbial growth on different impression material surfaces treated with disinfectants compared to control group was observed.

Dimenol [spray] showed more efficacy compared to $2 \%$ glutaraldehyde and UV radiation on alginate impression material i.e $46 \%, 31 \%$ and $44 \%$ respectively in reducing the microbial load. (Graph 1) Higher efficacy of Dimenol [spray] was also seen compared to $2 \%$ glutaraldehyde and UV radiation on polyvinyl siloxane impression material i.e 53\%, 35\% and $48 \%$ respectively. (Graph 2) Dimenol [spray] and UV radiation demonstrated equal efficacy i.e $49 \%$ as compared to $42 \%$ of glutaraldehyde on impression compound impression material. (Graph 3) Dimenol [spray] and UV radiation had comparable efficacy i.e $51 \%$ as compared to $39 \%$ of glutaraldehyde on zinc oxide eugenol material. (Graph 4)

Microwave disinfection showed more antimicrobial efficacy compared to $2 \%$ Glutaraldehyde, Dimenol [spray] and UV radiation. Zero values were obtained for the samples subjected to a microwave so has not been included in the statistical analysis 
Graph 1: Microbial count on Alginate control group and disinfected impression samples

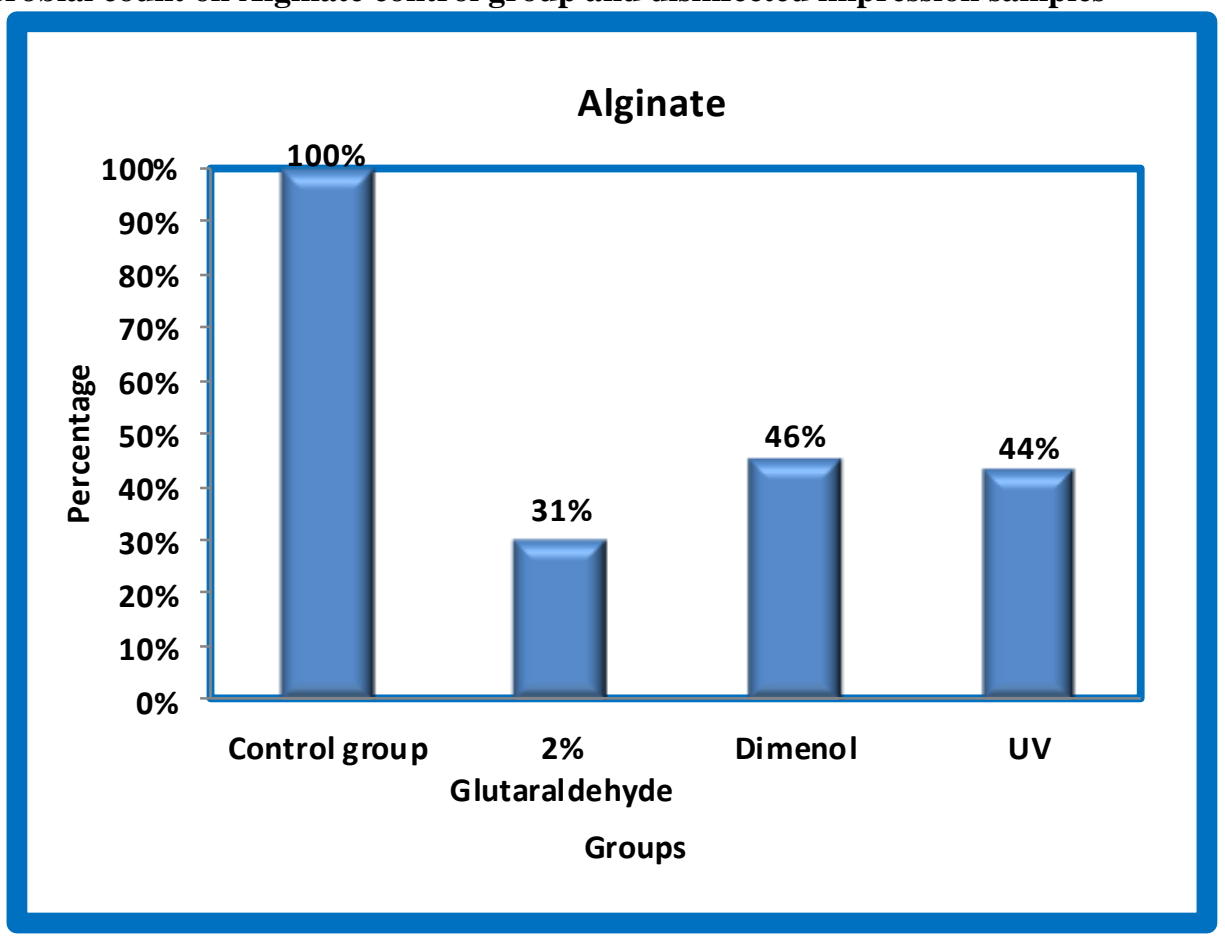

Graph 2: Microbial count on polyvinyl siloxane control group and disinfected impression samples

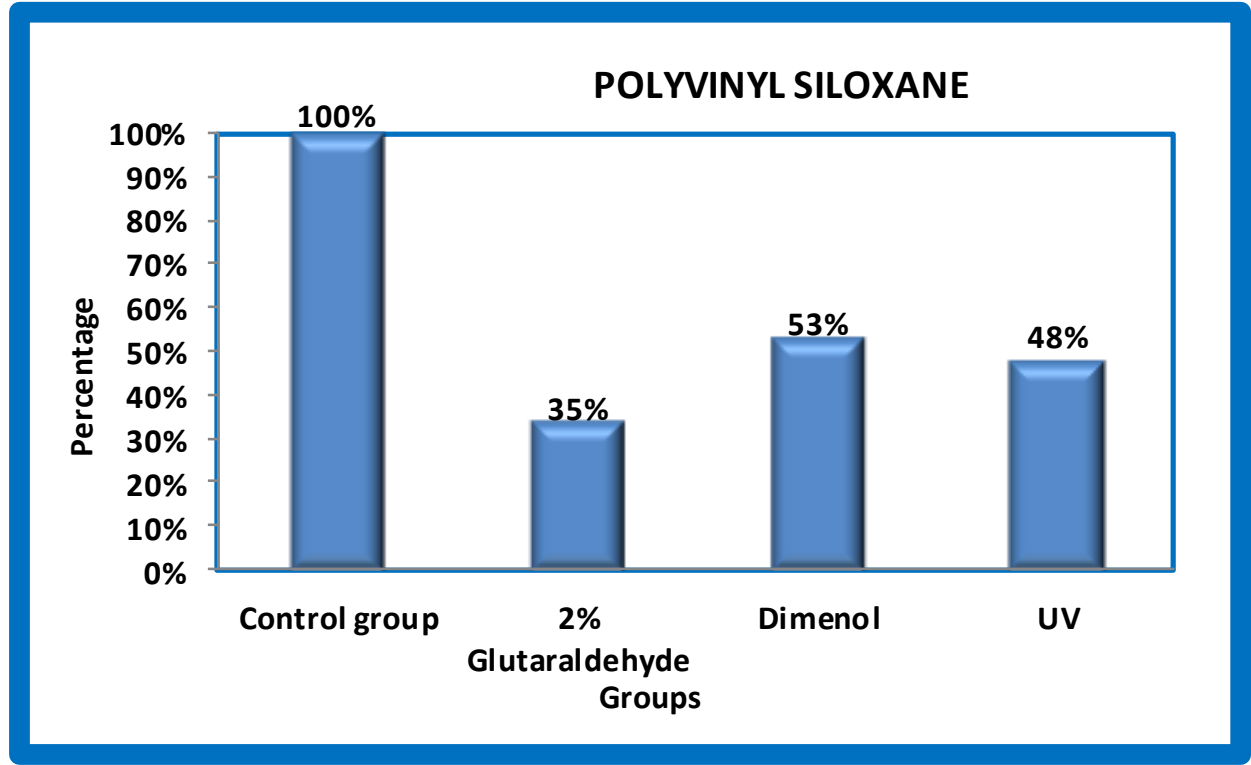


Graph 3: Microbial count on impression compound control group and disinfected impression samples

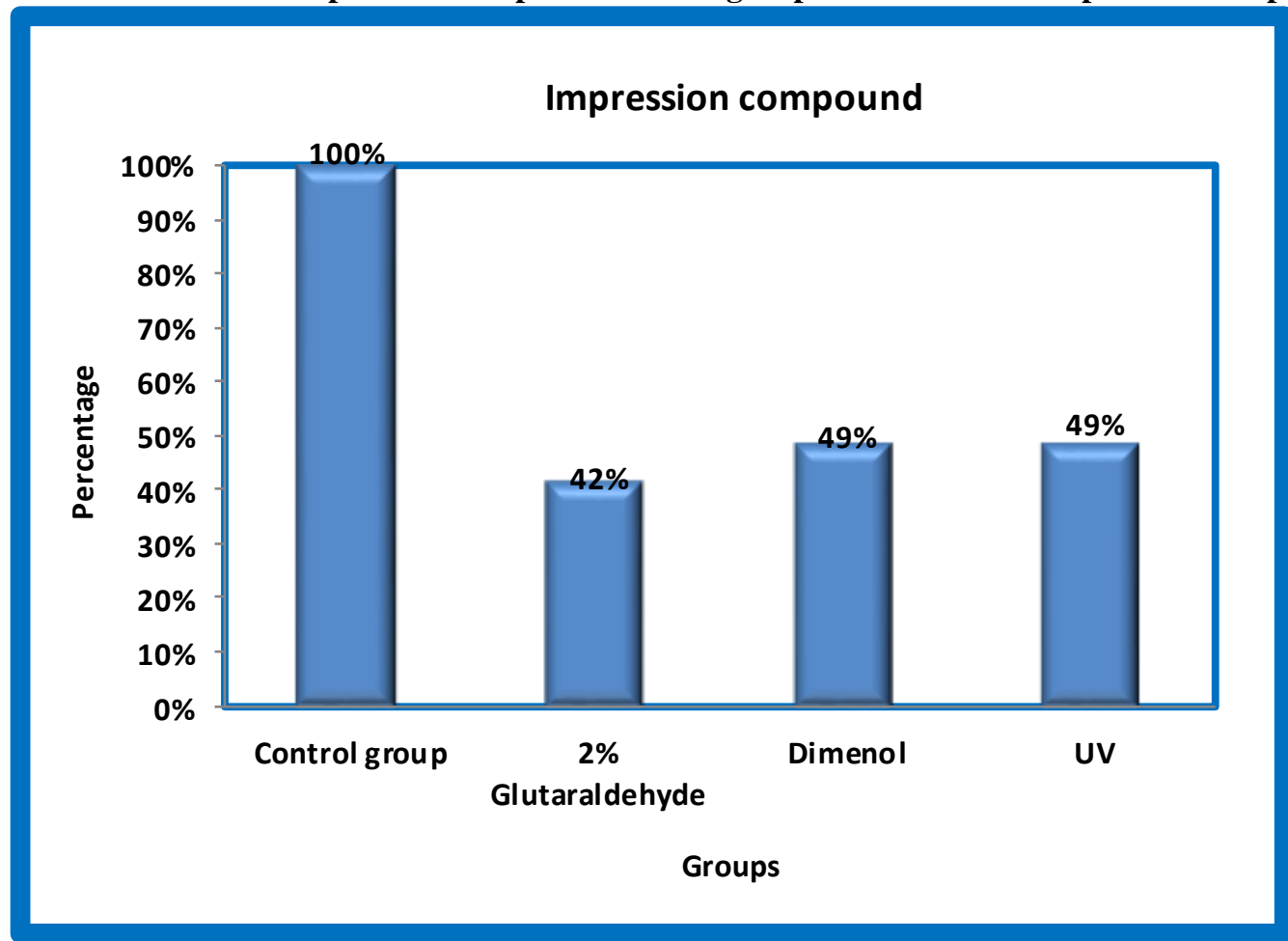

Graph 4: Microbial count on zinc oxide eugenol control group and disinfected impression samples

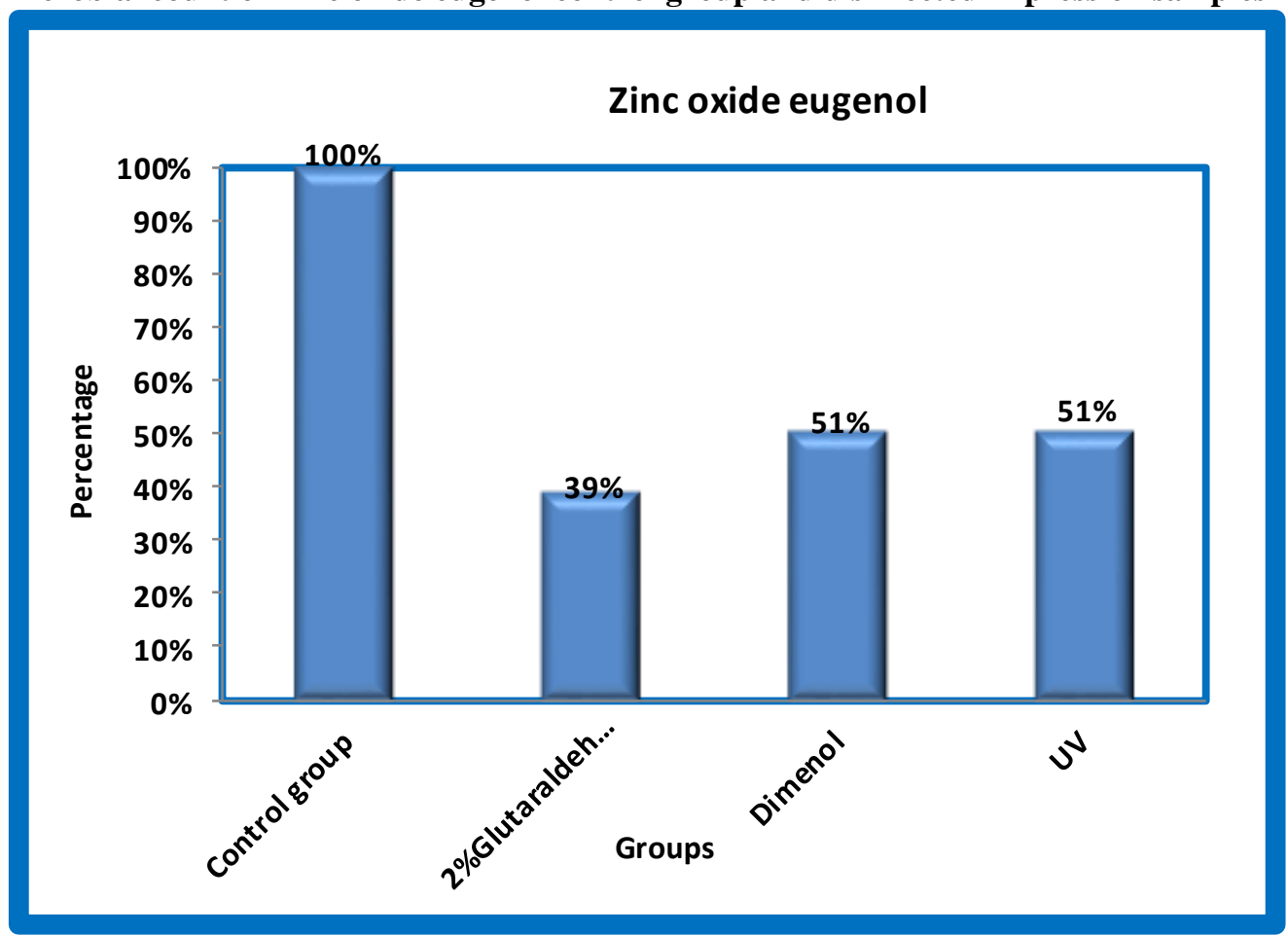




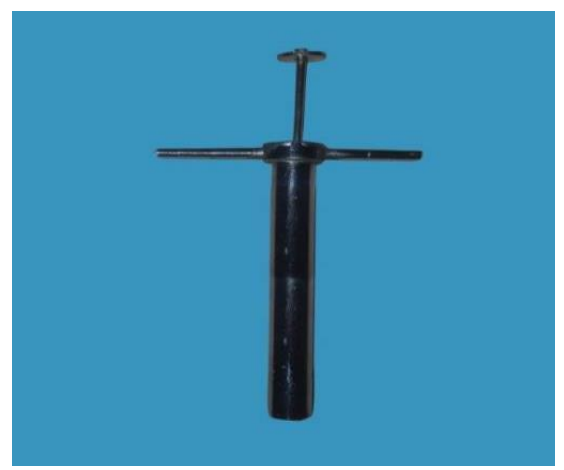

Fig. 1: Cork borer

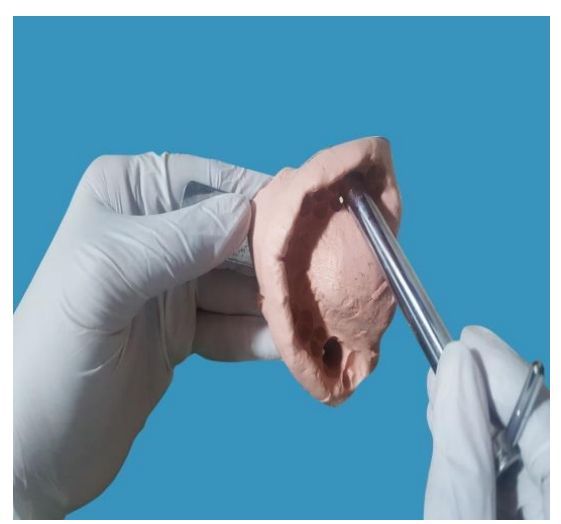

Fig. 2: Sample punching

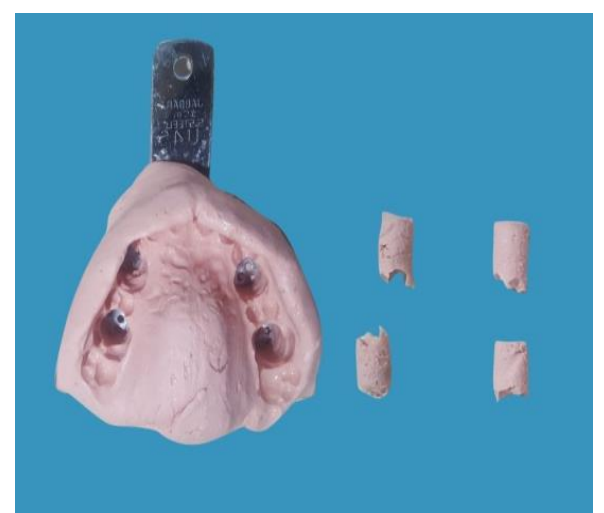

Fig. 3: Alginate samples

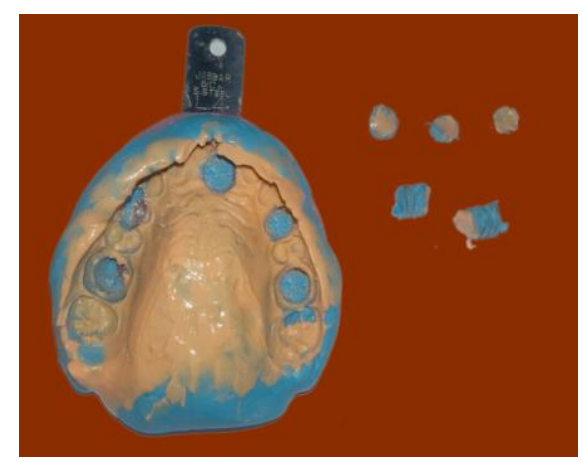

Fig. 4: Polyvinyl siloxane samples

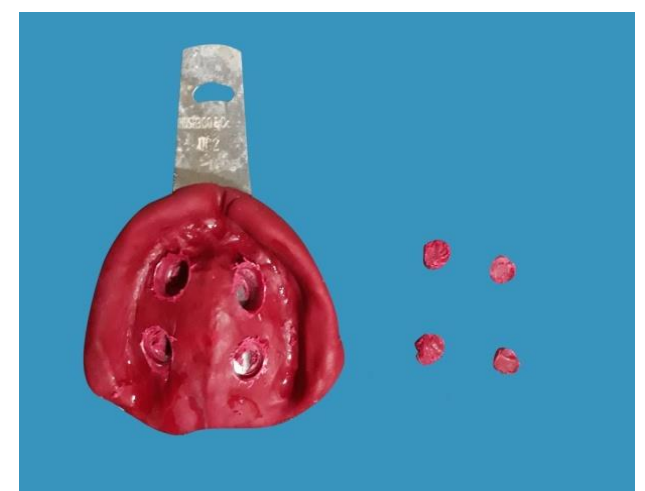

Fig. 5: Impression compound samples

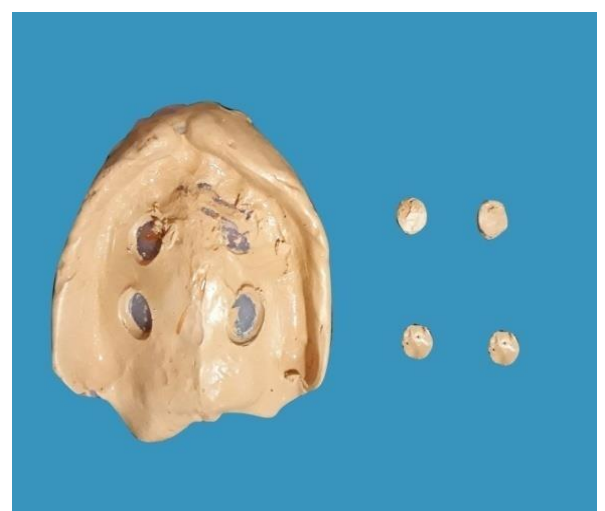

Fig. 6: Zinc oxide eugenol samples

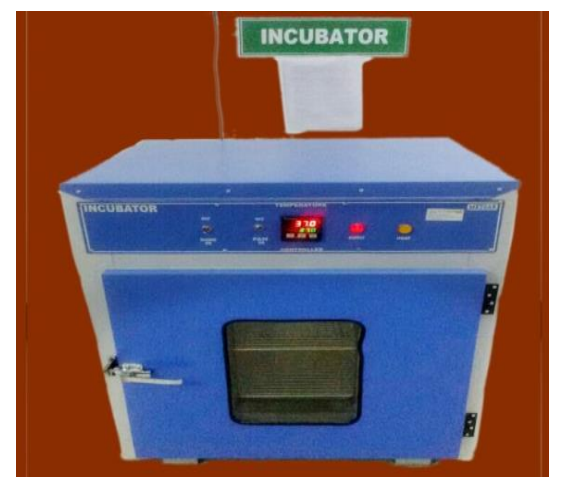

Fig. 7: Incubator

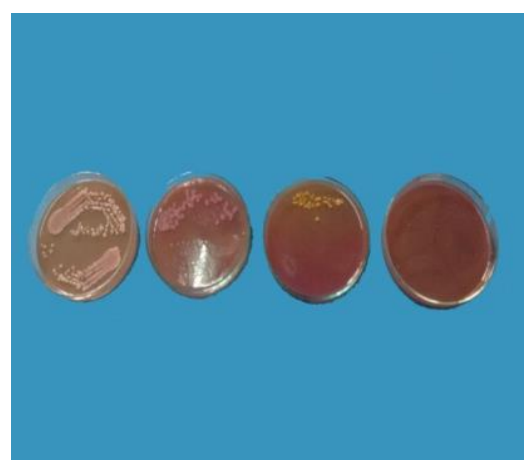

Fig. 8: Microbial growth 


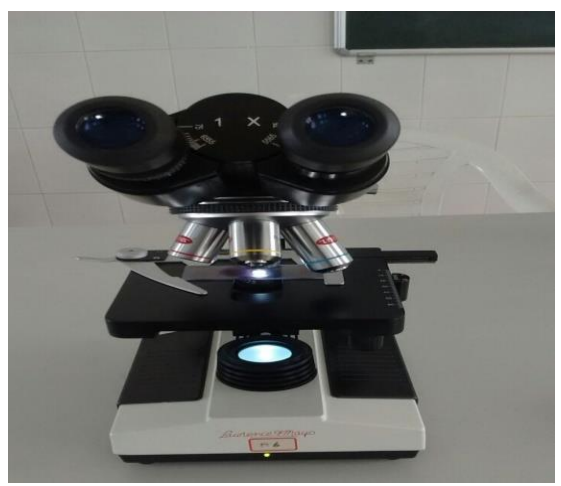

Fig. 9: Binocular microscope

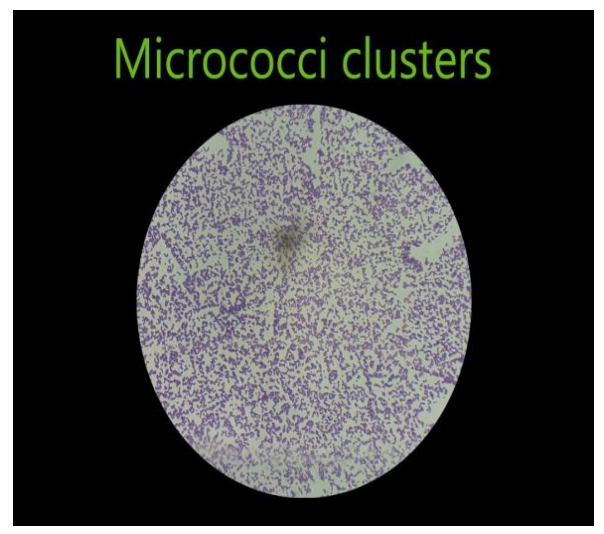

Fig. 10: Micrococci clusters

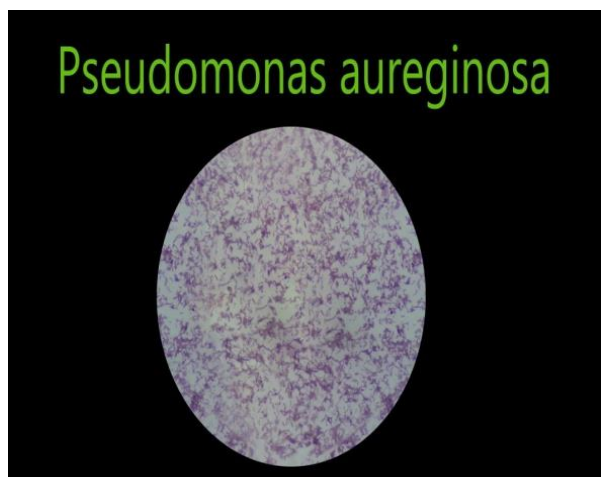

Fig. 11: Pseudomonas aureginosa

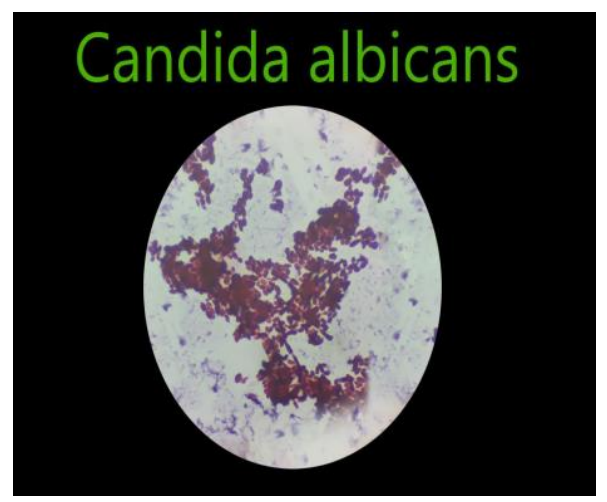

Fig. 12: Candida albicans

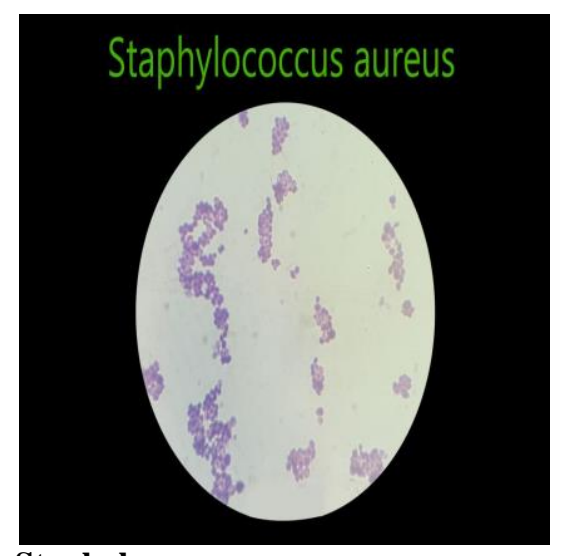

Fig. 13: Staphylococcus aureus

\section{Discussion}

The process which destroys many pathogenic microorganisms except bacterial spores is known as disinfection. Sterilization is a process that destroys or eliminates all forms of microbial life including bacterial spores in health-care facilities by means of physical or chemical methods. Earle H. Spaulding believed that the nature of disinfection could be readily understood if instruments and items for patient care were categorized as critical, semicritical, and noncritical according to the degree of risk of infection involved in the use of the items. ${ }^{3,4}$

It has been reported that $17.2 \%$ of prosthodontists have a positive HBV serologic blood marker, which is 6 to 7 times greater than in the general population. In addition, dental laboratory personnel may be relatively at a high risk of infectious diseases, and $14.2 \%$ of dental technicians showed a positive blood marker for $\mathrm{HBV}^{4}$

Bergman $^{5}$ reported that the entire dental staff is routinely exposed to numerous viral and bacterial pathogens that have the potential to cause serious illness. Schiff et al. ${ }^{6}$ showed that dental technicians have a significantly higher prevalence of HBV than the general population. Dental technicians may be at risk of HBV and other infections from laboratory material that have been in contact with a patient's blood and saliva although the degree of hazard of infection varies.

Powell et al. ${ }^{7}$ reported the contamination of $67 \%$ of all dental materials sent to the dental laboratories with the bacteria of varying degrees of pathogenicity. Therefore to prevent possible cross-contamination, sterilization is mandatory. Mycobacterium tuberculosis, hepatitis B virus (HBV), herpes simplex virus (HSV), and other pathogenic microorganisms can be transmitted by impressions. Other normal oral microflora, may become pathogenic and can cause opportunistic infections, especially in immunecompromised individuals.

Gross contamination of the impressions with saliva and blood can be eliminated by rinsing the impressions under running tap water immediately after removal from the mouth. However, Bergman ${ }^{5}$ (1989), $\mathrm{McNeill}^{8}$ 
(1992) and Beyerle ${ }^{9}$ (1994) reported that rinsing the impression materials with water alone is regarded as gross decontamination because it removes only $40-60 \%$ of bacteria. Rowe and Forrest ${ }^{10}$ suggested that dental impressions must always be disinfected to prevent infection because the interference of salivary mucins and the adhesive salivary proteins make it difficult to clear away all blood and saliva from impression surface with a simple washing.

Four methods of disinfection followed in this study are immersion method, a spray method, UV radiation and microwave irradiation. Disinfectants are $2 \%$ Glutaraldehyde for $10 \mathrm{~min}$ immersion ${ }^{11,12}$, Isopropyl alcohol spray [Dimenol] for $15 \mathrm{~min}^{13}$ and UV radiation for $3 \min ^{14,15}$ based on previous studies. The fourth method is microwave for polyvinyl siloxane at $650 \mathrm{~W}$ for $7 \mathrm{~min} .{ }^{16}$ The present study showed polymicrobial growth in control groups of all impression materials.

In the control group of this study, polymicrobial growth was observed. Microorganisms isolated were alpha-hemolytic streptococci, Candida albicans, Diphtheroid, E.coli, Enterococci feacalis, Klebsiella pneumonia, Micrococci, Pseudomonas aureginosa, Staphylococci aureus, Staphylococci albus, Streptococci viridians. The result of the study are near to the study carried out by Eugosa et al. ${ }^{12}$ Didem Atabek et al. ${ }^{17}$ and Samra et al. ${ }^{18}$ More microbial growth was observed on alginate as compared to the other three materials, the reason would be hydrophilic nature of the material. Similar findings were observed in previous studies. ${ }^{19,20}$

By the results, it was observed that the $2 \%$ Glutaraldehyde showed higher antimicrobial efficacy for disinfecting alginate, impression compound and zinc oxide eugenol. But for polyvinyl siloxane, Microwave radiation had higher efficacy compared to $2 \%$ glutaraldehyde. There was a marked reduction of microbial growth after disinfection with a disinfectant agent. $2 \%$ glutaraldehyde was more efficient in reducing the microbial load when compared with UV radiation and Dimenol [spray]. The UV radiation and Dimenol [spray] showed equal potential in reducing the microbial count but less efficient when compared to $2 \%$ Glutaraldehyde. But in polyvinyl siloxane microwave was more effective which had removed the microorganism completely compared to Glutaraldehyde. Similar results were obtained by Bhasin et al. ${ }^{16}$ and $\mathrm{Yu}$-Ri Choi et al. ${ }^{21}$ in their studies.

Glutaraldehyde has been classified as a higher level disinfectant, that destroys microorganisms, in particular, tubercle bacilli, HIV and HBV, by acting as a fixative reagent against proteins. The biocidal activity of glutaraldehyde results from the alkylation of sulfhydryl, hydroxyl, carboxyl and amino groups of microorganisms, which in turn alters synthesis of protein, DNA, and RNA. ${ }^{22} \mathrm{Li}$ et al. ${ }^{23}$ examined the germicidal power of $2 \%$ Glutaraldehyde which destroyed $99.99 \%$ of staphylococcus aureus.
Doddamani et al. ${ }^{24}$ observed that $2 \%$ Glutaraldehyde destroyed S. aureus and S. viridans effectively. Similar findings were found in this study.

Giammanco et al. ${ }^{25}$ reported $0.5 \%$ glutaraldehyde to be more effective in three tested conditions irrespective of the material used. Demajo et al. $^{26}$ concluded that glutaraldehyde [MD520] is more effective when compared with alcohol-based chemical disinfectants when both are used in spray form, particularly when alginate is used as an impression material.

Osama Al Jabrah et al. ${ }^{20}$ determined the antimicrobial effect of four disinfectants namely dimenol, perform ID, MD520 and has tabs on impression materials such as alginate, polyether, and polyvinyl siloxane. They demonstrated that elimination of microorganisms from the surface of the impressions were $100 \%$ successful with all the four disinfectants. Dahar et al. ${ }^{27}$ in 2017 evaluated the antimicrobial efficacy of $0.5 \%$ sodium hypochlorite and $2 \%$ glutaraldehyde disinfection solutions and concluded that both disinfectant agents effectively disinfected alginate impressions.

Some studies reported that $2 \%$ Glutaraldehyde in combination with other disinfectants showed higher efficacy than individually used. Eugosa et $\mathrm{a}^{12}$ evaluated combined use of $0.25 \%$ benzalkonium chloride with $2 \%$ Glutaraldehyde or $1 \%$ sodium hypochlorite are recommended for clinical and laboratory use.

Boylan et al. ${ }^{28}$ reported that disinfection by ultraviolet chamber had shown higher efficacy. They had recommended the use of this disinfection method as it reduced the surface contamination and did not produce any irritating vapors. Samra et al. ${ }^{18}$ evaluated that ultraviolet chamber is the most effective in reducing the microbial count when compared 2\% glutaraldehyde and sodium hypochlorite disinfectants.

Munagapati et al. ${ }^{29} 2011$ evaluated the efficacy of $2 \%$ glutaraldehyde and U.V. light as disinfectants and concluded that the immersion method of disinfection in $2 \%$ glutaraldehyde and U.V. light disinfection did not show any statistically significant dimensional change on polyvinyl siloxane impressions, but $2 \%$ glutaraldehyde showed comparatively more dimensional change than U.V.light.

Anand et al. ${ }^{30}$ in 2013 compared the efficacy of ultraviolet light (UV light) with direct current glow discharge in disinfecting Candida albicans coated elastomeric impression material and found that $\mathrm{U}-\mathrm{V}$ light exposure had more efficiently decreased the colony counts of C. albicans on samples when compared with direct current glow discharge exposure. Zhang et al. ${ }^{31}$, stated that UV radiation combined with $2 \%$ glutaraldehyde immersion exerts the highest effect upon the disinfection of HIV and HBV infected dental impressions compared with that of individual disinfection.

Himanshu et al. ${ }^{32}$ compared the usage of UV chamber for disinfection of various dental impressions 
at different time interval with $2 \%$ glutaraldehyde and stated that disinfection achieved with $2 \%$ glutaraldehyde for $10 \mathrm{~min}$ and UV radiation for $10 \mathrm{~min}$ was an equal amount.

In the present study, the efficacy of ultraviolet rays to disinfect the dental impression materials at $254 \mathrm{~nm}$ for $3 \mathrm{~min}$ was determined and was compared with $2 \%$ glutaraldehyde. In this study, UV radiation was found to be less effective when compared to $2 \%$ glutaraldehyde. This might be because of inadequate time or inadequate penetration of UV light onto the impression. $8 \mathrm{~W}$ bulb which was used might not be sufficient to kill the bacteria.

Dimenol [spray] showed less efficacy when compared to $2 \%$ Glutaraldehyde immersion and almost equal efficacy with UV radiation. The most likely explanation for the antimicrobial action of alcohol is denaturation of proteins.

Because of the different brands of impression material and different time duration of disinfection process used, it is not possible to review the results of this study with the others. This study showed the efficacy of the disinfecting procedures under clinical conditions against oral pathogenic bacteria and fungi. Further research is needed to investigate the efficacy of disinfectants, especially for viruses and resistant bacteria species.

\section{Conclusion}

Within the limitations of this study, it is concluded that all the three disinfecting agents were effective in minimizing the microbial load with $2 \%$ Glutaraldehyde being the most effective. Microwave showed complete removal of microorganism on polyvinyl siloxane impression surfaces at $650 \mathrm{~W}$ for $7 \mathrm{~min}$.

\section{Conflict of Interest: None.}

\section{References}

1. Infection control recommendations for the dental office and the dental laboratory. ADA Council on Scientific Affairs and ADA Council on Dental Practice. J Am Dent Assoc 1996;127:672-80.

2. Hugo WB. A Brief history of heat and chemical preservation and disinfection: A Review J Appl Bacteriol 1991;71:9-18.

3. Ahila SC, Subramanian E. Comparative evaluation of dimensional stability and surface quality of gypsum casts retrieved from disinfected addition silicone impressions at various time intervals: An in vitro study. J Dent Oral Hyg 2012;4:34-43.

4. William A. Rutala, David J. Weber and the Healthcare Infection Control Practices Advisory Committee (HICPAC) Guideline for Disinfection and Sterilization in Healthcare Facilities, 2008.

5. Bergman B. Disinfection of prosthodontic impression materials: A literature review. Int J Prosthodont 1989;2:537-42.

6. Schiff E, DeMedina MD, Kline SN. Veterans' administration co-operative study on hepatitis and dentistry positive for anti-HBc or anti HBs (or both). $J$ Am Dent Assoc 1986;113:390-396.

7. Powell GL, Runnells RD, Saxon BA, Whisenant BK. The presence and identification of organisms transmitted to dental laboratories. J Prosthetic Dent 1990;64:235-37

8. McNeill MR, Coulter WA, Hussey DL. Disinfection of irreversible hydrocolloid impressions: a comparative study. Int J Prosthodont 1992;5(6):563-67.

9. Beyerle MP, Hensley DM, Bradley DV Jr., Schwartz RS, Hilton TJ. Immersion disinfection of irreversible hydrocolloid impressions with sodium hypochlorite. Part I: Microbiology. Int J Prosthodont 1994;7(3): 234-8.

10. Rowe AH, Forrest JO. Dental impressions: the probability of contamination and a method of disinfection. Br Dent J 1978;145:184-186.

11. Egusa $\mathrm{H}$, Watamoto $\mathrm{T}$, Matsumoto T. Clinical evaluation of the efficacy of removing microorganisms to disinfect patient derived impressions Int J Prosthodont 2008;21:531-538.

12. Egusa H, Watamoto T, Matsumoto T. An Analysis of the persistent presence of opportunistic pathogens on patientderived dental impressions and gypsum casts. Int $J$ Prosthodont 2008;21:62-68.

13. Kaplan BA, Goldstein GR, Boylan R. Effectiveness of a professional formula disinfectant for irreversible hydrocolloid. J Prosthet Dent 1994;71:603-06.

14. Baysan A, Whiley R, Wright PS. Use of microwave energy to disinfect $a$ long-term soft lining material contaminated with Candida albicans or Staphylococcus aureus. J Prosthet Dent 1998;79(4):454

15. Bustos J, Herrera R, Gonzalez U. Effect of immersion disinfection with $0.5 \%$ sodium hypochlorite and $2 \%$ glutaraldehyde on alginate and silicone. Microbiology and SEM study. Int J Odontostomat 2010;4:169-77.

16. Bhasin A, Vinod V, Bhasin V, Mathew X, Sajjan S, Ahmed ST et al. Evaluation of Effectiveness of Microwave Irradiation for Disinfection of Silicone Elastomeric Impression Material. J Indian Prosthodont Soc 2013;13(2):89-94.

17. Atabek D, Alacam AD, Tuzuner E. In vivo evaluation of impression material disinfection with different disinfectant agents. Clin Dent Res 2009;33:52-59.

18. Samra RK, Bhide SV. Efficacy of different disinfectant systems on alginate and addition silicone impression materials of Indian and international origin. A comparative evaluation. J Indian Prosthodont Soc 2010;10:182-89.

19. Samaranayake LP, Hunjan M, Jennings KJ. Carriage of oral flora on irreversible hydrocolloid and elastomeric impression materials. J Prosthet Dent 1991;65:244-249.

20. Al-Jabrah O, Al-Shumailan Y, Al-Rashdan M. Antimicrobial effect of 4 disinfectants on alginate, polyether, and polyvinyl siloxane impression materials. Int J Prosthodont 2007;20:299-307.

21. Choi YR, Kim KN, Kim KM. The disinfection of impression materials by using microwave irradiation and hydrogen peroxide. J Prosthet Dent 2014;112(4):981-87.

22. MCDonnell G and Russel AD. Antiseptics and Disinfectants: Activity, Action, and Resistance. Clin Microbiol Rev 1999;12:147-179

23. Li X, Li O, Li T. Experimental observation on microbicidal activity of a complex Glutaraldehyde disinfectant. Zhonghu Liu Ing Bing Xue Za Zhi 1996;17(5):292-95.

24. Doddamani S, Patil RA, Gangadhar SA. Efficacy of various spray disinfectants on irreversible hydrocolloid impression materials. An in vitro study. Indian J Dent Res 2011;22:764-69. 
25. Giammanco GM, Melilli D, Rallo A. Resistance to disinfection of a polymicrobial association contaminating the surface of elastomeric dental impressions. New Microbial 2009;32:167-72.

26. Demajo JK, Farrugia C, Millan-Sango D, Sammut C, Valdramidis V, Camilleri J. Effectiveness of Disinfectants on Antimicrobial and Physical Properties of Dental Impression Materials. Int J Prosthodont 2016;29: 63-67.

27. Dahar E, Kaur J. Antimicrobial Efficacy of Immersion $0.5 \%$ Sodium Hypochlorite And 2\% Glutaraldehyde Disinfectants on Alginate Impressions. IOSR J Dent Med Sci 2017;16:11-14.

28. Boylon RJ, Goldstein GR, Schulman A. Evaluation of an ultraviolet disinfection unit. J Prosthet Dent 1987;58:650-654.

29. Munagapati B, Mallikarjun, Jayasree K. Comparison of efficacy of glutaraldehyde and UV light disinfection and their effect on dimensional stability of polyvinyl siloxane impressions an in-vitro study. Annals and Essences of Dentistry 2011;3:13-5.

30. Anand V. Comparison of UV C Light and Chemicals for Disinfection of Surfaces in Hospital Isolation Units. $J$ Pharm Bioallied Sci 2013;5:80-4.

31. Zhang W, Mao H, Zhou G. Effect of ultraviolet radiation combined with immersion disinfection of silicone impressions infected with hepatitis B virus and HIV. Biomed Res 2017;28:6377-80

32. Aeran H, Sharma S, Kumar V, Gupta N. Use of Clinical UV Chamber to Disinfect Dental Impressions: A Comparative Study. J Clin Diagn Res 2015;9:ZC67-70.

How to cite the article: Devi DD, R. Himabindu. A Comparative study on efficacy of various disinfectant systems on dental impression surfaces: In vivo study $\mathbf{J}$ Dent Specialities 2018;6(2):100-108. 